\title{
La reivindicación del paisaje urbano histórico a través del espacio público. El centro de Ciudad Juárez como escenario simbólico de análisis
}

\author{
The revindication of the historical urban landscape through public space. The \\ downtown of Ciudad Juárez as a symbolic scenario of analysis
}

Recibido: diciembre 2019

Aceptado: septiembre 2020

\section{Resumen}

El interés del presente artículo es abordar la reivindicación del paisaje urbano histórico a través del espacio público y su relación con las prácticas y los imaginarios con la intención de establecer la importancia de incluir estos elementos al cuestionarse sobre las formas mediante las cuales se interviene, percibe y preserva el paisaje urbano histórico.

Para ello, se han desarrollado 32 entrevistas en profundidad en dos tipologías de actores distintas relacionados con el centro de Ciudad Juárez, las cuales mediante análisis de discurso, han permitido enfatizar en los aspectos tangibles e intangibles que dotan de significado el centro histórico puntualizando en el espacio público, las prácticas sociales y los imaginarios urbanos.

Entre los principales hallazgos, se destacada que la implementación de espacios públicos en la zona centro de la ciudad que en relación con la asignación de significados a determinados edificios patrimoniales, permite ampliar las dinámicas de interacción en dicho espacio, lo que resulta en la generación de lugares y prácticas que se orientan a la vinculación con el carácter patrimonial asignando valores positivos a las formas de percibir el centro y por lo tanto del paisaje urbano histórico.

\section{Palabras Clave:}

Centro histórico; espacio público; imaginarios urbanos; paisaje urbano
Raúl Holguín Ávila ${ }^{1}$

\begin{abstract}
The interest of this article is to address the revindication of the historic urban landscape through public space and its relationship with practices and imaginary with the intention of establishing the importance of including these elements when questioning the ways in which it is intervened, perceived and preserves the historical urban landscape.

To this end, 32 in-depth interviews have been carried out in two types of different actors related to the downtown of Ciudad Juárez, which, through discourse analysis, have allowed emphasizing the tangible and intangible aspects that endow the historical center with meaning in the public space, social practices and urban imaginary.

Among the main findings, it stands out that the implementation of public spaces in the downtown area of the city that in relation to the assignment of meanings to certain heritage buildings, allows to expand the dynamics of interaction in said space, resulting in the generation of places and practices that are oriented to the link with the patrimonial character assigning positive values to the ways of perceiving the center and therefore the historic urban landscape.
\end{abstract}

\section{Keywords:}

Historic downtown, public space, urban imaginaries, urban landscape

\footnotetext{
1 Nacionalidad: mexicano; adscripción: Instituto de Arquitectura Diseño y Arte de la Universidad Autónoma de Ciudad Juárez; Doctor en Planeación Urbana por la Universidad Autónoma de Baja California; e-mail: raul.holguin@uacj.mx
} 


\section{ANTECEDENTES}

En este artículo, se exponen una serie de elementos teórico-metodológicos que tienen como principal objetivo analizar los elementos y dinámicas que favorecen a la reivindicación del paisaje urbano histórico a través del espacio público, los imaginarios urbanos y las prácticas.

Para ello, se tomó como escenario de análisis El Centro Histórico de Ciudad Juárez, ubicado en el Estado de Chihuahua, México; dicho espacio se localiza al norponiente de la ciudad y no corresponde al centro geográfico de la misma. Entre sus características cabe mencionar que el centro es un área que comprende lo que inicialmente se denominó Misión de Nuestra Señora de Guadalupe de Mansos del Paso del Río del Norte (Paso del Norte), fundada en 1659 y siguiendo el modelo tradicional de las ciudades fundadas por españoles en las cuales, se encuentra en un primer cuadro el mercado, la iglesia y el ayuntamiento, teniendo como centro la plaza de armas y siguiendo una traza ortogonal.

Asimismo, el centro es un área limítrofe hacia el norte con EUA vinculada mediante los puentes internacionales Santa Fe y Lerdo, teniendo además elementos físicos históricos con valor cultural y patrimonial. También resulta importante mencionar, que el centro constituye un espacio relevante en la estructura urbana al ser constantemente utilizado por diversos tipos de usuarios producto de la convergencia actual y recurrente de servicios, comercio, movilidad y diversos usos vigentes, no obstante, es importante señalar que la connotación histórica y la actividad de usos en la zona, se han visto impactados principalmente en los últimos diez años por la implementación de una serie de intervenciones institucionales, que han tenido como finalidad principal la generación o recuperación de espacios públicos, lo que conlleva a plantear la pregunta del presente trabajo, la cual fue conocer la incidencia de las intervenciones en materia de espacio público que, en relación con las prácticas y los imaginarios han impactado en la reivindicación del paisaje urbano histórico del centro de Ciudad Juárez como escenario simbólico de análisis.

$\mathrm{Al}$ establecer la relación que puede suscitarse entre componentes tangibles e intangibles en el abordaje del paisaje urbano histórico y su reivindicación a través del espacio público, se establecen las pautas para realizar un abordaje que permite ampliar las perspectivas de análisis de un espacio complejo como lo es el centro, generando herramientas teórico metodológicas principalmente de carácter cualitativo, que dado el enfoque empleado, han permitido el abordaje amplio de las connotaciones objetivas y subjetivas que conlleva el estudio del paisaje urbano histórico y el espacio público en sus diversas dimensiones.

\section{BREVE APROXIMACIÓN SOBRE EL DEBATE DEL PAISAJE URBANO HISTÓRICO}

Al plantear el abordaje teórico conceptual de lo que implica hablar de paisaje urbano histórico, remite en sí mismo a considerar una complejidad inmediata ante un concepto que hasta hace menos de veinte años era inexistente y que por ello se encuentra aún en discusión. Esto implica encontrarse con una serie de posturas que han ido incluyendo distintas dimensiones y reflexiones para su definición mismas que van desde lo arquitectónico, lo sustentable, económico e incluso la percepción del sujeto.

Sin embargo, es importante mencionar que un principio básico para adentrarse en este concepto y sus implicaciones tiene un origen institucional, toda vez que la UNESCO en 2011 establece la definición de paisaje urbano histórico como "la zona urbana resultante de una estratificación histórica de valores y atributos culturales y naturales, lo que trasciende la noción de "conjunto" o "centro histórico" para abarcar el contexto urbano general y su entorno geográfico" (UNESCO, 2011, p. 62). Ello implica la necesidad de "dejar de ver a los centros históricos como islas urbanas aisladas de su entorno y reconocer su carácter dinámico y adaptable planteando que criterios como la "conservación", "autenticidad" e integridad" son más utopías que posibilidades concretas y que el desafío es, más bien, gestionar adecuadamente los cambios de las ciudades y sus centros históricos" (Sepúlveda, 2017, p. 146).

Asimismo, al considerar la complejidad inherente a este concepto y su articulación con diversas escalas en la trama urbana, también se manifiesta la necesidad de cuestionarse sobre la integración de los distintos elementos tanto objetivos como subjetivos que no pasan desapercibos en el abordaje y definición del paisaje urbano histórico. Es decir, la concepción dinámica de la ciudad y los procesos de cambio en donde las subjetividades son poco 
abordadas en esta temática.

Lo anterior conllevaba entonces a la ampliación del significado del paisaje urbano histórico en cuanto a su aplicación, pues bien, no es sólo asumir que se trata de un concepto cuyo alcance está estrictamente aplicado a un especio determinado como el centro histórico y sus componentes físicos estáticos, sino que alude a una diversidad de escalas y dimensiones en la trama urbana articuladas entre sí en donde la idea de centro histórico es parte de ello.

Aunque el propio abordaje sobre las características del paisaje urbano histórico resulta complejo, hay elementos que bien pueden sintetizar el sentido del concepto en mención, en tanto que se pone de manifiesto como señala el trabajo de Lalan (2011) la necesidad en la preservación del patrimonio urbano, así como de concebir la ciudad como ente dinámico y como conjunto antes de aislar el área patrimonial. Si bien pueden encontrarse diferencias en cuanto al abordaje de lo que implica el paisaje urbano histórico, la idea sobre la preservación o conversación se podría relacionar en todo caso al objetivo de gestionar el paisaje y los conjuntos urbanos históricos para su preservación, lo que también incluye las dimensiones objetivas y subjetivas.

El abordaje de la discusión del paisaje urbano histórico permite entonces establecer a grandes rasgos los alcances que supone dicha temática para los fines del presente trabajo. Si bien se establece la idea de considerar algo más que centros históricos en las reflexiones sobre el tema, el legado patrimonial tangible e intangible referente al caso de estudio presentado para este trabajo da paso una preocupación legítima, que lejos de reducir el análisis a un elemento territorialmente definido, busca analizar las formas mediante las cuales se ha hecho una reivindicación del mismo mediante la gestión del espacio público, donde las prácticas, los imaginarios y la sustentabilidad conforman una parte importante para ello.

\section{EL ESPACIO PÚBLICO EN LOS CENTROS HISTÓRICOS}

En el entendido de que el presente trabajo se centra en el abordaje del centro histórico como lugar de análisis en la reivindicación del paisaje urbano histórico a través del espacio público, es conveniente precisar lo referente a este último concepto en tanto que las diversas relaciones posibles en el espacio público dentro del contexto urbano, llevan a situarlo "como el espacio más familiar de las ciudades, es decir, las calles y las plazas, los patios y los parques, fungiendo como agentes de nuestra cohesión" (Sorkin, 2004, pág. 13). La diversidad de espacios que pueden ser acotados dentro de lo público, refieren a una presencia constante de los mismos dentro de la trama urbana, mismos que pueden catalogarse en una amplia variedad de funciones además de agentes de cohesión como se expresa en Sorkin, en tanto que se encuentra un referente temporal que sitúa al espacio público como una constante en la vida urbana.

Asimismo, al hablar de espacio público se hace alusión a un elemento presente en la cotidianidad de la vida en las ciudades, así como referentes de uso colectivo y espacios de apropiación en sus diversas dimensiones. Sin embargo, el considerar el espacio público como una constante en la cotidianidad de los sujetos y su marco urbano de vida, emerge la consideración de la permanencia en las funciones y dimensiones de este, ya no sólo en lo social, sino también en lo ambiental, pues bien, situar el espacio público como una constante, implica a su vez, considerar sus configuraciones en la temporalidad espacial de la vida en las ciudades. En este sentido, resulta importante mencionar que "históricamente han sido los centros fundacionales de las ciudades los espacios públicos por antonomasia y, pese a los cambios que han experimentado en términos de su centralidad, siguen concentrando parte importante del equipamiento cultural de las ciudades y muchas de las actividades económicas" (Sepúlveda, 2017, p. 151).

Además del carácter dinámico, colectivo e incluso temporal que guarda el espacio público en su relación con el centro histórico, también es concebido como aquel espacio "donde pueden leerse las estructuras de la integración social" (Habermas, 2006, pág. 28), lo que en relación al pensamiento de Bourdieu, se enfatiza en la interpretación del espacio público "como un conjunto de relaciones o un sistema de posiciones sociales que se definen las unas en relación con las otras" (Bourdieu, 2000, pág. 14), por lo que se alude a la incorporación del sujeto desde su concepción individual en un espacio colectivo, donde la convergencia de posturas y contradicciones no deja de estar manifestada al relacionarse con las posiciones sociales que se asumen en la trama del espacio público y los elementos tangibles e intangibles que lo constituyen. 
Al contextualizar el espacio público en el marco de un espacio central como lo es el centro histórico, se expresa la condición multidimensional sobre la construcción y concepción del espacio en mención, en donde no obstante, es importante identificar categorías sobre lo público para una mejor comprensión distinguiendo cuatro en particular, a decir, "el espacio público físico como equipamiento colectivo, el espacio público físico como trama urbana, el espacio público "no físico" donde se llevan a cabo las interacciones, y por último, el espacio público-público, es decir, el espacio imaginario donde se da la práctica política" (Castañeda \& García, 2007, pág. 37). Con el desarrollo de las categorías mencionadas, puede aludirse a una perspectiva de mayor amplitud sobre lo que implica hablar de espacio público, por lo que no sólo puede entenderse como un espacio más de la trama urbana, sino como un elemento que incluye en sí mismo una diversidad de dinámicas, significados, prácticas y sujetos que le otorgan características particulares a cada una de las representaciones del espacio público, mismo que además "constituye parte del capital social" (Neira, 2007, pág. 33). En este sentido, "es el espacio público a un tiempo el espacio principal del urbanismo, de la cultura urbana y de la ciudadanía. Es un espacio físico, simbólico y político" (Borja \& Muxí, 2000, pág. 8)

Por lo anterior, resulta necesario repensar el espacio público como una serie de sistemas interrelacionados de objetos y acciones, en los cuales las categorías arquitectónicas, perceptivas e inclusive artísticas, ofrecen esa connotación simbólica del espacio, desde donde se exponen una serie de significados en primera instancia individuales, pero que dadas las diversas categorías del espacio, se ve expresada en una colectividad social traducida en la asignación de formas, funciones, dimensiones, símbolos y procesos interpretativos para la construcción y la producción del significado social del espacio, donde la presencia del plano físico, es un elemento complementario en ese proceso recíproco entre lo tangible y lo intangible, los elementos biofísicos y sociales, los cuales se integran en las prácticas donde confluyen los sujetos para tejer la vida social en un espacio determinado que en este caso se sitúa en el contexto del centro histórico.

Al considerar la producción social del espacio público y sus significados en un contexto determinado, las cualidades que pueden identificarse dentro de dichos espacios permiten otorgarle una carga diferenciada de aquellos cuyas características simbólicas significativas sean inexistentes, es decir, el espacio público como lugar en un contexto histórico.

\section{LA INCORPORACIÓN DE LAS PRÁCTICAS SOCIALES EN EL ESPACIO PÚBLICO}

Al vincular las prácticas sociales con el espacio público, alude a la composición de un concepto con diversos alcances en el entendimiento de los sujetos bajo determinadas características, historicidad, cotidianidad y un marco espacio temporal, que sitúa su actuar bajo un referente de conocimiento construido y acordado. Las dimensiones del espacio y su connotación de público en las prácticas sociales, no resultan desvinculadas al estudio espacial de la ciudad, por lo que se señala que "las prácticas sociales son definidas como productoras de una espacialidad que incluye la producción y la reproducción, las localizaciones particulares y los conjuntos espaciales característicos de cada formación social, siendo además presentada como medio y resultado de la actividad, del comportamiento y de la experiencia humana...por último, los espacios de las representaciones envuelven simbolismos complejos, algunas veces codificados, otras no, siendo éste el espacio directamente vivido, el espacio de los habitantes y los usuarios" (Contreras Delgado, 2006, págs. 114-116).

El adentrarse en los alcances y referentes teóricos de las prácticas sociales más allá de su composición espacial, permite una amplia connotación en la composición de dicho concepto, en donde la vida social como un conjunto de relaciones integradas por intereses de diversos sujetos, se vincula con ese mundo de los objetos. Asimismo, al precisar teóricamente en lo referente a las prácticas sociales estas pueden entenderse como "operaciones multiformes y fragmentarias, relativas a ocasiones y detalles, insinuadas y ocultas en los sistemas de los cuales estas operaciones constituyen los modos de empleo, y por tanto desprovistas de ideologías o de instituciones propias obedeciendo a determinadas reglas (...) en donde la formalidad de las prácticas puede encontrarse lo referido a las prácticas de lectura, prácticas de espacios urbanos, utilizaciones de rituales cotidianos, nuevos usos y funcionamientos de la memoria a 
través de las "autoridades" que hacen posibles (o permiten) las prácticas cotidianas." (De Certeau, 2000, págs. XLV-XLVI)

En lo señalado por Certeau, pueden identificarse aquellos elementos que favorecen al desarrollo de las prácticas cotidianas y que no forman parte de una teorización académica, sino que constituyen las realidades de los sujetos y su interactuar en diversos escenarios de vida. No obstante, otro elemento importante está vinculado al tiempo, en tato que la relación entre las prácticas y el tiempo conlleva a situar las posiciones entre el sujeto y el objeto con un elemento recurrente y continuo que acompaña el tiempo, es decir, el espacio.

La relación de reciprocidad entre sujeto y objeto vinculada a la estructuración de la práctica social supone además de la continuidad espacio temporal y la institucionalidad objetiva de la sociedad, la necesidad de ambas para que los sujetos organicen su acción y su relación con los otros, "las personas no pueden satisfacer sus necesidades sino actuando coordinadamente con los demás. Esto exige que existan previamente algunas reglas que aseguren ciertos grados mínimos de coherencia y predicción a esas relaciones. Por la otra parte está la necesidad vital de las personas de poseer un grado de autonomía y de identidad propia para darle un sentido a su actuar. Esto es lo que aporta la subjetividad" (Güell, Frei, \& Palestini, 2009, pág. 70).

Asimismo, es importante mencionar que la realización de las prácticas sociales también está vinculada a la existencia de reglas, destacando dos procesos: la interiorización del contexto y el conocimiento de este, permitiendo a los sujetos interactuar de un modo y no de otro. Mediante estos procesos, se adquiere la capacidad de establecer y crear reglas para la ejecución de las prácticas sociales a través de la interiorización del mundo de vida de los sujetos, es decir, se manifiesta la existencia de un conocimiento sobre las formas de estructurar la vida cotidiana, por lo que se generan homogeneidades que permitan llevar acabo las prácticas sociales, no obstante, aquellos fenómenos que impactan la cotidianidad del mundo de vida de los sujetos, ameritan un conocimiento para interiorizar la trascendencia espacio-temporal de dicho fenómeno y establecer reglas que se ajusten al impacto de determinados fenómenos para la ejecución de las prácticas sociales, aunque en este punto, la interiorización de nuevos fenómenos no puede ser producto del conocimiento inmediato de los impactos espacio temporales, sino que en todo caso, conllevaría a procesos graduales de interiorización, por lo que las reglas para llevar las prácticas podrían no ser homogenizadas en un corto tiempo.

Al posicionar lo objetivo y lo subjetivo para la comprensiónyanálisis de las prácticas, se eestablecen enfoques de conocimiento para una definición de dicho concepto el cual puede entenderse como las formas cotidianas a partir de las cuales los sujetos en una temporalidad espacial dada, construyen objetiva y subjetivamente su mundo de vida en una relación dialéctica, formulando independientemente de la individualidad sistemas de relaciones y leyes, en relación con las representaciones, creencias, vivencias y sentimientos que están presentes en los propios sujetos; para llevar acabo las interacciones de ciertos modos y no de otros en el diario vivir.

En el entorno del centro histórico, la intención de analizar la incidencia de dichas intervenciones para le preservación del paisaje urbano histórico, tiene gran relación con la forma en la que mediante estas intervenciones se recuperan, consolidan o instauran prácticas que permiten otorgar nuevas perspectivas sobre esta zona y que por ende, fomentan otras formas de interactuar en y con el espacio contemplando los efectos que ello genere.

\section{LA CONSTRUCCIÓN DE LOS IMAGINARIOS URBANOS: CUALIDADES SUBJETIVAS DEL ESPACIO PÚBLICO}

La construcción de los imaginarios urbanos, incluyen una dinámica social permanente en la construcción del espacio, por ello, los imaginarios urbanos permiten de acuerdo con Louiset (2001), otorgarle inteligibilidad y hacer visibles ciertos procesos urbanos que desde las diversas miradas de lo material y tangible, dejan en la penumbra o directamente invisibilizan. No obstante, es pertinente aclarar de acuerdo con Lindón (2007) que estas miradas de lo material y tangible, han sido y siguen siendo relevantes para entender ese territorio complejo y multidimensional que llamamos ciudad y los procesos urbanos que ahí acontecen.

Al incorporar los imaginarios urbanos en los procesos que se dan en las ciudades, se está enfatizando en lo subjetivo para devolver la voz y los sentidos a los mismos usuarios de la ciudad que pueden considerarse como los sujetos que en ella interactúan. Los imaginarios urbanos, 
tratan entonces de explorar las condiciones que caracterizan la vida urbana y su expresión en las sociedades contemporáneas, donde las formas de entender los diversos espacios en los que se constituye la trama urbana se han visto modificadas a través de lo perceptivo, lo cognoscitivo, lo simbólico y en general del espacio dotado de significados.

Este mismo concepto, es definido por Armando Silva "como el uso e interiorización de los espacios y sus respectivas vivencias dentro de la intercomunicación social, por lo que dan cuenta de las múltiples ciudades que conforman la ciudad, aquellas demarcadas no sólo por las topografías sino las que produce y revela la topografía simbólica" (Silva, 1992, pág. 15).

Al considerar los usos y la interiorización de los espacios para determinar diversas connotaciones de la ciudad desde quienes la viven y la sienten, se pone de manifiesto la diversidad en cuanto a las formas de concebir la ciudad y sus espacios, ya no sólo como parte de un entorno de vida, sino como espacios con elementos simbólicos que permiten diferenciar un espacio de otro desde diversas posturas, donde Gorelik (2004), aborda a los imaginarios urbanos como una reflexión cultural sobre las más diversas maneras en que las sociedades se representan a sí mismas en las ciudades, donde construyen sus modos de comunicación y sus códigos de comprensión de la vida urbana y la imaginación urbana como dimensión de la reflexión político-técnica (por lo general, concentrada en un manojo de profesiones: arquitectura, urbanística, planificación) acerca de cómo la ciudad debe ser.

La dimensión espacio temporal que permea los imaginarios urbanos, refiere al dinamismo que pueden contener en cuanto a su construcción, no sólo por la experiencia del sujeto, sino por el contenido simbólico de esos lugares sobre los cuales se identifica algo, por lo que en cualquier caso según Cornelius Castoriadis, el imaginario urbano es "una creación incesante de figuras, formas e imágenes, a partir de las cuales solamente puede uno referirse a algo" (Castoriadis, 1985, pág. 7).

Los imaginarios urbanos pueden ser vistos como una serie de procesos determinados por una temporalidad espacial en la cual los sujetos, a través de su cotidianidad y su experiencia de vida, interiorizan la ciudad y los símbolos que los componen, asignando significados y percepciones, generando una diversidad de lugares dentro de la misma ciudad.

Dichos espacios no refieren a una generalidad urbana, sino a una interiorización fragmentada vinculada a las dinámicas y prácticas sociales a través de las cuales los sujetos han construido su experiencia de vida, en donde además, dicha interiorización se ve complementada por la carga simbólica atribuida a determinados elementos tangibles e intangibles que constituyen el espacio, misma que puede mantenerse o mutar con el paso del tiempo, ya que las dinámicas sociales no son del todo estáticas y los elementos físicos del espacio no siempre permanecen constantes en su estructura o usos.

Por ello, se apunta a los procesos con los cuales los sujetos en relación con su experiencia de vida pueden generar una imagen particular del mundo, o bien, de los espacios que conforman su diario vivir. En estos procesos, los sujetos pueden auxiliarse de su imaginación y articular lo vivido en diversas proyecciones mentales, formas, imágenes, figuras y significaciones simbólicas sobre el mundo y el espacio que los rodea, donde el conocimiento formulado a través de su experiencia de vida y las prácticas efectuadas le permite realizar representaciones imaginadas y significados construidos y producidos por dimensiones sociales y físicas que favorecen en su interactuar con el mundo. Sin embargo, dichas representaciones imaginadas podrían ser selectivas, puesto que se ven articuladas por aquellos elementos tangibles e intangibles vinculados en las prácticas sociales y que pueden resultar representativos, simbólicos, identitarios y significativos en la vida de los sujetos y su interactuar colectivo.

\section{METODOLOGÍA DE ESTUDIO}

Con un enfoque cualitativo, se aplicaron un total de 32 entrevistas en profundidad tomando criterios espacio temporales para la definición de los actores participantes, de tal manera que fueron abordados aquellos actores que a través de su experiencia de vida en el centro, podían referir sobre las configuraciones espaciales, en los usos y las prácticas, la existencia de elementos simbólicos y los fenómenos que han impacto en la zona

En este sentido, se definieron dos criterios principales para establecer la temporalidad en la selección de los actores, el primer de ellos, se refiere a una permanencia como residente en la zona centro mayor a treinta años, mientras que el 
segundo considera a quienes tengan más de treinta años residiendo en Ciudad Juárez, pero no dentro del centro y que visiten la zona regularmente

Las entrevistas realizadas se aplicaron en el mismo sitió de estudios con horarios diversos y en locaciones variadas como viviendas, comercios $\mathrm{u}$ oficinas, exceptuando el segundo grupo de actores, donde principalmente las entrevistas se llevaron a cabo en viviendas particulares y negocios. Es importante mencionar que las entrevistas realizadas son parte de un proceso más amplio en la recopilación de información en campo, misma que incluyó observación participante por un periodo de seis meses en distintos horarios y días en el centro de Juárez. Para la transcripción de las entrevistas se utilizó el programa Atlas-ti aplicando un análisis por categorías que permitiera inferir en la relevancia de elementos específicos (imaginarios, prácticas, interacciones) en la reivindicación del paisaje urbano histórico a través del espacio público.

\section{EL CENTRO DE CIUDAD JUÁREZ COMO CASO DE ESTUDIO}

Con un área total de 165.74 ha, el polígono definido institucionalmente como centro histórico por el Instituto Municipal de Investigación y Planeación (IMIP) se comprende por un total de nueve colonias que son: Chamizal, Centro, Bellavista, Monumento, Cuauhtémoc, Barreal, La Chaveña, Partido Romero y Barrio Alto (ver imagen 1). De este conjunto de colonias que comprenden lo denominado centro histórico, se obtiene una serie de características relevantes, que de acuerdo con el Inventario Nacional de Vivienda, con datos del Instituto Nacional de Estadística, Geografía e Informática (INEGI) 2015 son las siguientes: El total de la población de este polígono es de 3,872 habitantes, siendo la población de 30 a 59 años la que mayor presencia tiene con un $40 \%$. Asimismo, es importante considerar que aunque se trate del primer cuadro de la ciudad, no se contabiliza el $100 \%$ de las viviendas ubicadas en este polígono con la totalidad de servicio sanitario, agua entubada, drenaje, energía eléctrica y recubrimiento de piso.

Imagen 1. Delimitación del centro histórico de Ciudad Juárez

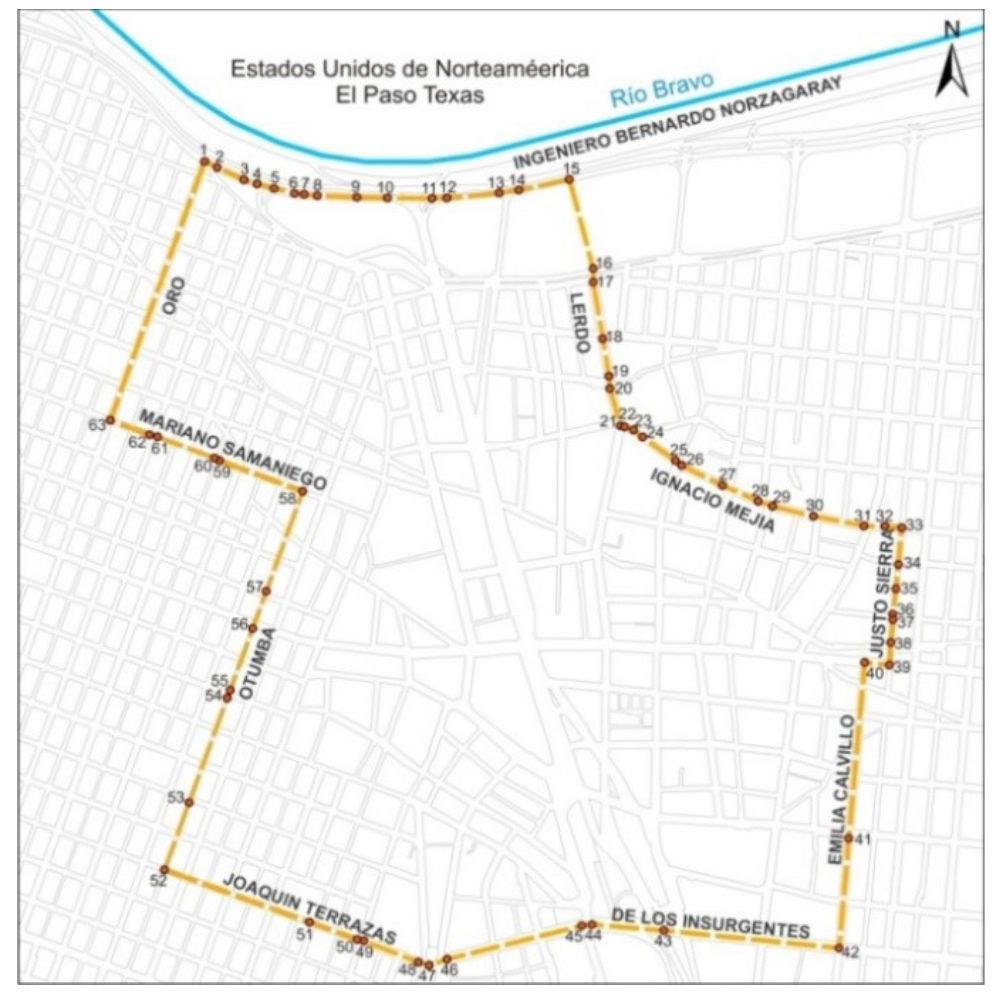

Fuente: Plan Maestro de Desarrollo Urbano del Centro Histórico de Ciudad Juárez, IMIP, 2013 
Algunas de las intervenciones recientes que van desde la remodelación de plazas hasta la creación de nuevos espacios peatonales y recreativos tienen origen en el 2006 con la construcción de la Plaza del Periodista y la remodelación del Monumento a Benito a Juárez y más recientemente la peatonalización de la Av. 16 de septiembre en 2014 y la creación de la Plaza Juan Gabriel en 2016 con la participación de distintos niveles de gobierno (ver imagen 2).

Imagen 2. Espacios públicos en el centro de Ciudad Juárez

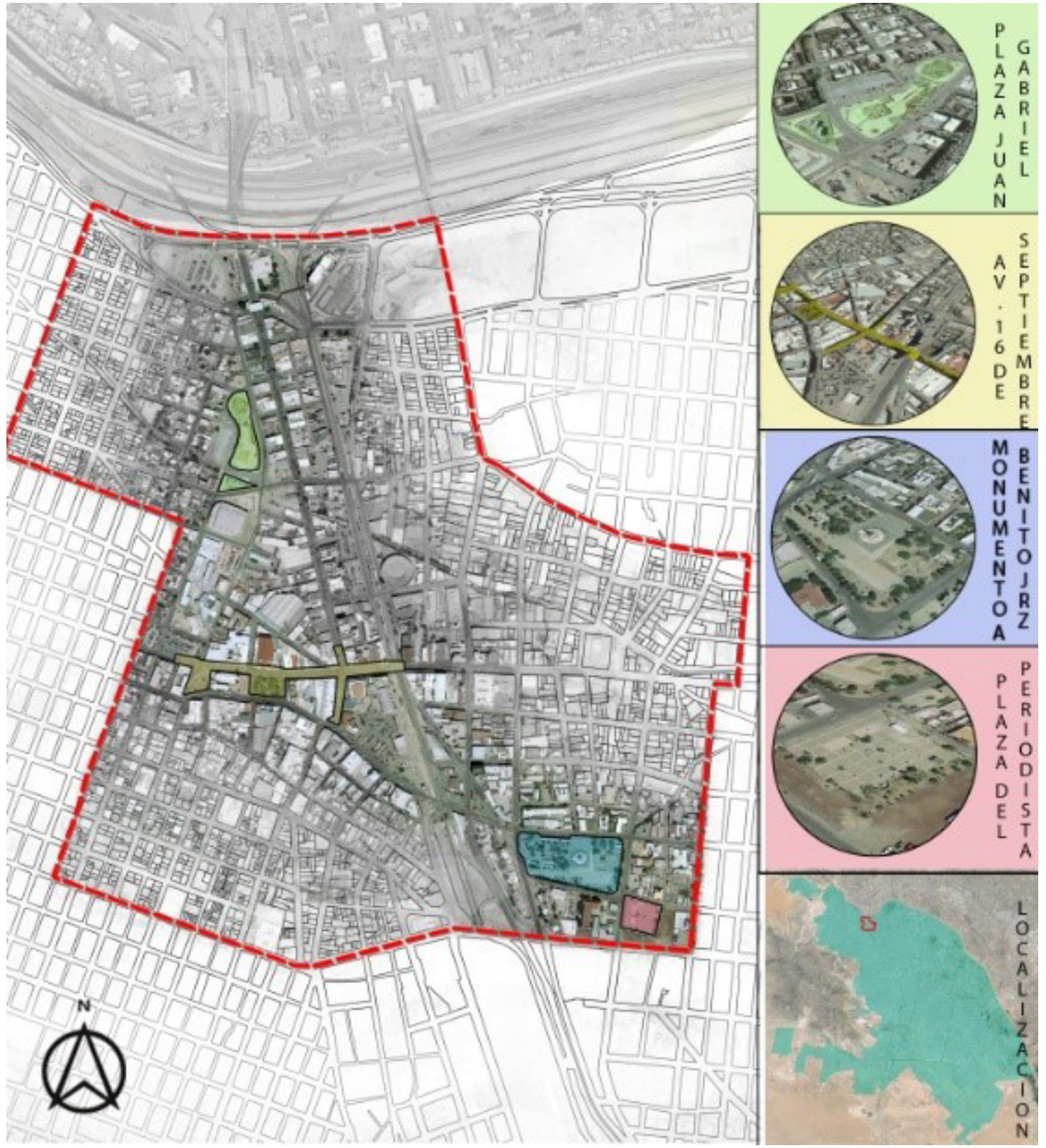


Otro elemento de importancia es que además en este sector de la ciudad se concentran doce edificios catalogados como patrimoniales de acuerdo con Instituto Nacional de Antropología e Historia, los cuales son: Templo Misión de Guadalupe, Antigua Presidencia Municipal, Museo de la Ex Aduana (Museo de la Revolución en la Frontera), Garita de Metales, Casa del Administrador, Plaza de Armas, Monumento a Benito Juárez, Centro Escolar Revolución, Hotel Sur, Templo Bautista, Edificio San Luis y Edificio Sauer (ver imagen 3).

Imagen 3. Edificios patrimoniales zona centro

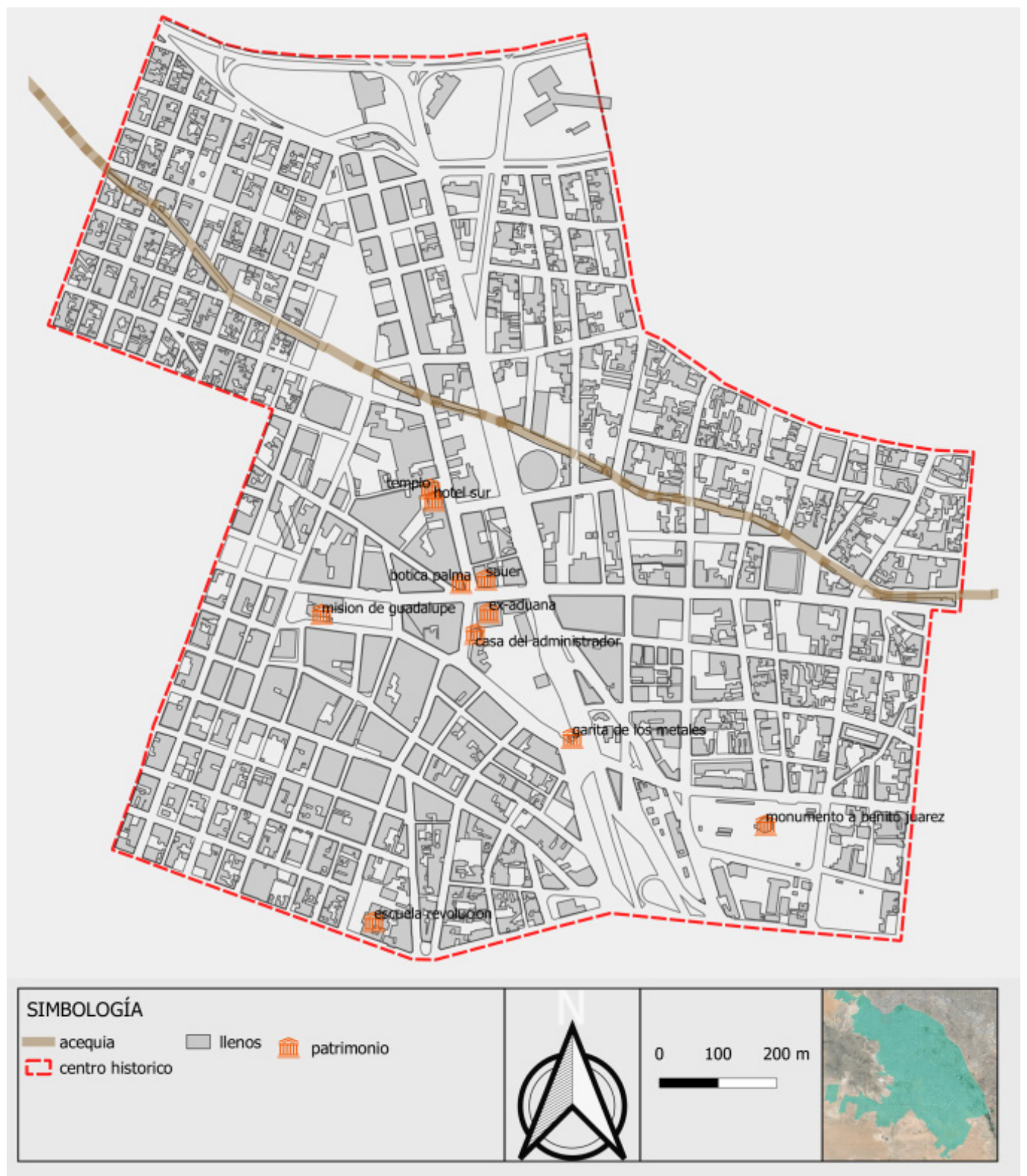

Fuente: Elaboración propia 


\section{EL IMPACTO DE LAS}

\section{TRANSFORMACIONES EN LA ZONA CENTRO PARA LA REIVINDICACIÓN DEL PAISAJE URBANO HISTÓRICO}

\section{El posicionamiento temporal en la percepción del centro}

Una primera aproximación que fue coincidente en ambos grupos de actores alude principalmente a la necesidad de establecer un comparativo temporal en relación con las características que permean la zona centro en un comparativo que parte del antes en relación con el ahora. Pues bien, esto permite clasificar distintos momentos desde los cuales los entrevistados han ponderado determinados elementos sobre otros los cuales principalmente se dividen en las dinámicas sociales y los aspectos físicos de la zona.

La información obtenida de las entrevistas permite establecer una noción amplia en cuanto al conocimiento que los entrevistados tienen sobre los distintos momentos mediante los cuales, a través de su interacción con la zona, han descrito las realidades percibidas detallando particularidades que sin embargo, se vuelve más nítidas al recurrir al propio relato de los entrevistados para establecer diferenciaciones espacio temporales del antes y el ahora, lo que también arroja los primeros indicios en la identificación de modificaciones suscitadas principalmente en la configuración espacial del centro y los impactos sociales que esto produjo.

Por lo anterior, se mantiene una memoria sobre el centro que aporta conocimientos para construir socialmente dichos espacios a través del tiempo, en tanto que se hace una expresión respecto a lo que fue y ya no es, es una modificación en las formas, las prácticas y las representaciones, lo que lleva a situar la zona en la actualidad.

"Siempre he estado aquí en el centro, aquí nací, aquí crecí y todo, hay cosas que siempre han estado aquí, son parte de la historia de la ciudad, por ejemplo misión y catedral, es un edificio, son más bien edificios que siempre están con gente, pero la vista que ahora tienen, ahora cuando se hizo peatonal la 16 (calle) cambió la forma en cómo se ve...y no nomás eso, en sí la forma en la que se ve el centro y la calle como tal"'(Hombre, 50 años residiendo en El centro histórico).

“A mí me tocó desde muy joven esta idea del centro como lugar de diversión, esta onda de la vida nocturna de la zona...si lo ves con esa idea de la diversión se puede decir que esto ha sido algo que no se ha ido del todo, ha tenido sus altibajos y aunque las mejoras que han hecho para pues que se vea mejor en si el centro son tardadas o muchos no las aprueban, también es cierto que pues le da otros aires al sector, porque pues hay más opciones de este... caminar por ejemplo, eso cambia todo, nunca ibas a pensar que ahora el lugar donde este se daban algunos servicios...pues prostitución pues para ser exactos, fuera ahora una plaza que si tú vas por ejemplo una noche de verano, la ves llena de mucha gente de todas las edades, eso cambió todo aquí y todos los que vivimos lo notamos rápido" (Mujer, 35 años residiendo en el centro histórico).

"Últimamente han hecho algunas mejoras en el centro, tampoco no es que vaya muy seguido, pero por lo menos una vez al mes me gusta ir. Ese lugar siempre ha tenido gente por alguna u otra razón siempre hay personas. $\mathrm{Si}$ me pongo a pensar cómo era el centro hace quince años por ejemplo, era un lugar sucio y con no muy buena imagen, aunque tenía algunos atractivos como el monumento a Juárez, la ex aduana que siempre se vio como un edificio distinto o la catedral entre algunos otros que están ahí, pero recientemente han cambiado cosas, quizá es porque se ve más bonito que ves más personas en el centro, inclusive ver actividades culturales sobre la 16 (calle peatonalizada en 2014) le da un sentido diferente a la imagen del centro" (Hombre, 66 años viviendo en Ciudad Juárez).

"Si tu vienes por ejemplo un domingo o un sábado al medio día o en la tardes, vas a ver cómo la calle se utiliza de otro modo, antes puros carros, la cantinas y los bares siguen estando quizá ya no como antes, también es cierto que es inseguro, aunque te diré que el centro siempre ha tenido una famita de inseguridad... si han cambiado las cosas eso no se puede negar, aunque aún falta mucho por hacer, por rescatar la historia de la ciudad que está aquí... han cambiado cosas como te decía, quizá ahora hay más oportunidad de apreciar el centro porque hay espacios que antes no, quizá pueda verse con mayor detalle eso que pues hace diferente al centro del resto de la ciudad" (Hombre, 52 años viviendo en Ciudad Juárez). 


\section{Las configuraciones espaciales y sociales en el centro: claves en una nueva percepción}

La idea manifestada desde los actores participantes sobre las configuraciones en el espacio tanto físico como socialmente y los impactos en las formas mediante las cuales este se utiliza en una comparativa temporal, pone de manifiesto una parte importante asignada a la idea del cambio en esa zona. Se trata entonces de una percepción que se articula con nuevos elementos que permiten trazar otras perspectivas relacionadas a lo que es el centro, en comparación con una apreciación previa de la zona donde actualmente existe una convergencia en la aceptación puntual de los cambios.

Esto conlleva a replantear aquello que actualmente es aceptado socialemte en el centro, lo reconocido por los entrevistados como parte de las prácticas que de acuerdo a las condiciones físicas que actualmente determinan el espacio se vincula con eso. La convivencia en nuevos espacios, la realización de eventos culturales y las interacciones que mantienen con los otros, permiten puntualizar en aquello que hace posible entender esa representación de el centro a través de lo expresado por los entrevistados, aludiendo a "la objetividad que asegura el consenso sobre el sentido de las prácticas, es decir, el acuerdo entre el sentido práctico y el sentido objetivado, en la producción de un mundo de sentido común" (Bourdieu, 2008, pág. 94).

"Existe la posibilidad ahora de utilizar el centro de otros modos que antes podríamos decir eran más limitados. El hecho de contar con alternativas de lugares donde estar o realizar algunas actividades recreativas pues de un modo u otro también permite poder estar en contacto con los demás, o sea en pocas palabras podemos estar caminando o viendo alguna presentación musical un domingo sobre la calle, antes para que eso sucediera pues las opciones eran limitadas. Esto no quiere decir tampoco que la zona sea segura totalmente, pero al menos hay opciones para tener otro tipo de actividades para la gente en general, algo que en algún tiempo había dejado de suceder" (Mujer, 48 años viviendo en el centro histórico).

Asimismo, la constancia en la descripción de los cambios acontecidos en la zona permite considerar un impacto de importancia de estos en la vida social y en las formas mediante las cuales se percibe dicho espacio, destacando la asignación de significados que se ven traducidos en la concepción que se tiene de la zona en un sentido positivo:

"Se han realizado algunos cambios que este pues vienen a favorecer la imagen de la zona, como todo hay gente en contra y gente a favor, pero en lo general se han realizado algunas modificaciones que pues si son importantes para lo que viene siendo el centro, por la imagen que se da y por la rehabilitación que de algún modo se intenta hacer, aún faltan muchas cosas claro está, pero las intervenciones que han tenido lugar aquí pues si aportan a que se aprecie de otra manera y sobre todo que se vean personas en el centro, que conviva la gente ahí" (Hombre, 35 años viviendo en Ciudad Juárez).

"Podría decirse que hay una valoración positiva respecto a los cambios que se han dado en la zona, tanto en la recuperación de espacios, la adecuación que han tenido así como en la posibilidad de que tengan lugar la convivencia de las personas en espacios que eran prácticamente inexistentes en la zona... esto además implica pensar que pueden hacerse más y mejores cosas, o bien, que pues pudieron hacerse mejor, sin embargo eso no demerita el hecho de que han favorecido a la condición que se tenía del centro que generalmente era muy negativa" (Hombre, 44 años viviendo en Ciudad Juárez)

Bajo estas apreciaciones sobre las características de usos y prácticas en la zona centro, la asignación de una valoración positiva refiere a una articulación dada entre las configuraciones en ese espacio y las formas en las que se percibe a las personas utilizando esos espacios, que en todo caso, permiten tener lugares para estar, más allá de la dinámica de flujo constante que pueda tener el centro asociado como lugar de tránsito.

\section{Los imaginarios urbanos en la valoración del centro}

Las formas mediante las cuales se describen cambios y con ellos nuevas dinámicas en cuanto a la ocupación y utilización de ciertos espacios en el 
centro, permiten tener referentes de importancia mediante los cuales se otorgan significados a ese espacio. En lo que refiere a la construcción de los imaginarios urbanos, los entrevistados perciben y construyen el espacio socialmente a partir de conocimientos adquiridos por sus propias experiencias de vida, lo que conlleva a explorar las condiciones que caracterizan las relaciones de los sujetos con ese espacio que no deja de ser público a través de las representaciones, lo cognoscitivo, lo simbólico y en general del espacio dotado de significados.

$\mathrm{Al}$ establecer la importancia de la experiencia de los entrevistados y sus formas de comprender el centro, se permite vislumbrar perspectivas sobre la generación de imaginarios creados en función de su experiencia en relación con ese entorno de interacción social y físico permitiendo en una primera aproximación, vincular con el imaginario urbano lo simbólico y sus significados en relación con este espacio.

Con anterioridad se ha manifestado lo referente a las modificaciones acaecidas en un marco espacio temporal dentro del centro, ya sean las prácticas, los usos y la apreciación del propio centro lo que ha dado pauta para obtener representaciones desde los entrevistados sobre este, permitiendo establecer nuevos símbolos dotados de significado, pues bien, el centro dejó de ser lo que era para convertirse en lo que es, un lugar para estar.

Sin embargo, al considerar el centro en su generalidad como un referente simbólico, es preciso aunar en los detalles que ello concierne, pues la información obtenida permite establecer que dentro de este existen múltiples elementos significativos que se asocian a la experiencia de los entrevistados, sus representaciones y sus afectos del estar ahí y no en otro lugar, lo que deriva en elementos simbólicos físicos y sociales.

En este sentido, en el centro se observan en una primera aproximación, símbolos físicos particulares que determinan el espacio, de tal modo, que se encuentran elementos tangibles y reconocibles que adquieren una importancia en particular, a decir, la misión de Guadalupe, la ex aduana, plaza de armas, catedral, la avenida Juárez y la avenida 16 de septiembre por mencionar algunos que se encuentran como un referente significativo que acompaña a las representaciones visuales del centro:

"cuando pienso sobre las cosas que hay en el centro y que yo crea significativas, te puedo decir que está la ex - aduana, la Juárez y catedral, porque son cosas que además de que siempre han estado aquí, yo las vi llenas de vida, siempre con gente... aprendí la historia de esos edificios porque mis papas me dijeron que era parte de la historia de Juárez, entonces desde muy temprana edad les di digamos relevancia" (Hombre, 50 años residiendo en el centro histórico).

"las cosas más significativas que puede haber en el centro, es la ex - aduana, la misión de Guadalupe y la ex - presidencia, por lo que representan en la vida de Ciudad Juárez, porque son cosas que siempre han sido importantes para la ciudad y son de lo más relevante que puede haber aquí, eso hace que uno sepa que está en el centro y no en otro lado" (Hombre, 64 años residiendo en el centro histórico).

"Hay cosas que tienen una importancia aunque mucha gente no sepa porque, o sea sabes que son relevantes incluso hasta porque se ven diferentes, es algo que si tú tienes viniendo un tiempo al centro en algún momento tuviste que haber visto... con el paso de tiempo han cambiado, podría pues decirse que para mejorar...esas cosas que han estado aquí y que podría digamos dárseles valor son la misión de Guadalupe por ejemplo, la ex aduana, la ex presidencia, plaza de armas inclusive más reciente la propia 16 de septiembre que vino pues a dar otra vista al centro y si te detienes un poco mientras caminas, te das cuenta que incluso catedral o la ex aduana se ven diferentes, es como si fuera una forma más atractiva de ver el centro, de recorrerlo y como no, hasta darle una importancia que quizá no le habías dado por nunca detenerte a ver, ahora puedes hacer eso" (Mujer, 38 años residiendo en Ciudad Juárez)

Es importante señalar que además del reconocimiento de símbolos físicos particulares, anteriormente se habló sobre nuevas dinámicas surgidas en el centro, donde los elementos físicos referenciados como relevantes forman parte al integrarse en el conjunto de lo definido como centro, por lo que las dinámicas sociales que en ellos se generan o bien a sus alrededores comprobadas a través de la observación, forman parte de esas características intangibles pero complementarias entre la relación de lo social y el plano de lo físico, lo cual, se constituye como 
una reciprocidad necesaria para la asignación de significados.

En este sentido, al ubicar elementos simbólicos significativos en estructuras físicas en particular, no reduce al imaginario urbano a un objeto, sino que en todo caso, es a través del objeto, que se manifiestan elementos inmediatos de significado, encontrando en la imagen a través de lo físico, elementos particulares que le permiten a los individuos consolidar su imaginario. Por lo anterior, la construcción de los imaginarios urbanos en relación con el centro histórico de Ciudad Juárez se constituye en este caso a partir de la significación de elementos físicos y procesos de interacción social que cobran importancia en tanto que estos pueden generar referencias sobre lo que es la zona, mismos que a su vez son plenamente identificables y se caracterizan como relevantes al momento de otorgar cualidades que pueden ser descritas y valoradas.

Con ello, la relación entre lo social y lo urbano, no sólo supone una interacción del individuo con las características físicas del espacio que lo rodea, sino que esas características han pasado de ser componentes físicos del espacio, a símbolos que refieren a las representaciones generadas de la zona centro, donde de acuerdo a Salvador Salazar (2010), las representaciones encuentran su manifestación concreta en los relatos, pues éstos realizan la transformación de los lugares en espacios, mismos que además, en este caso, contiene elementos suficientes para extrapolar el relato a su escenario de vida actual, en donde dichos elementos, se ven referidos a los componentes físicos que figuran como vestigios urbanos que pueden dar un soporte a la representación del espacio.

Es importante señalar que mediante la relación de lo social con los componentes físicos y las configuraciones espaciales del área, las prácticas e interacciones que se generan en relación con esos elementos tangibles determinan esa otra parte intangible en la valorización de la zona centro y que inclusive, se relaciona con las formas mediante las cuales ahora este espacio de la ciudad es recorrido (ver imagen 4).

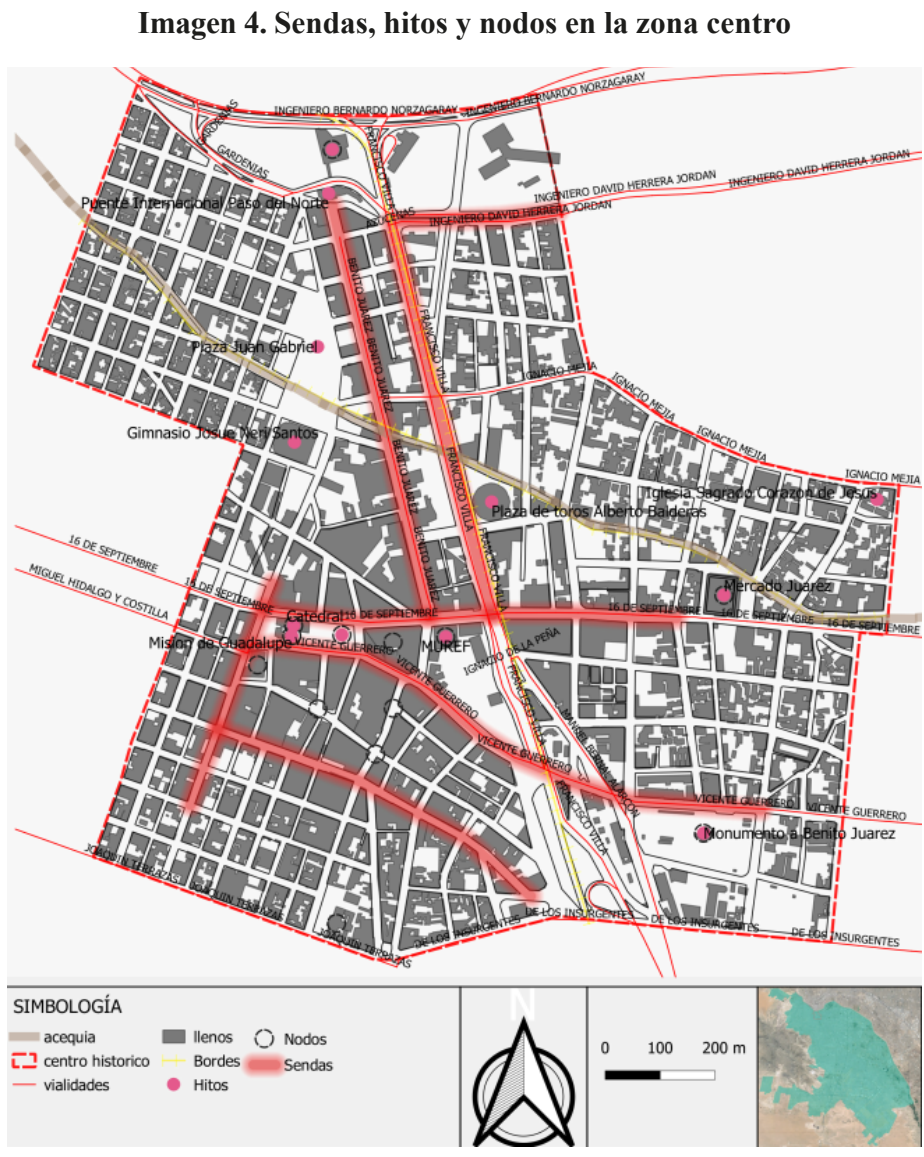

Fuente: Elaboración propia 


\section{CONCLUSIONES: LA TRASCENDENCIA DEL ESPACIO PÚBLICO EN LA REIVINDICACIÓN DEL PAISAJE URBANO HISTÓRICO}

La relación de las dinámicas sociales y los elementos físicos existente en el centro histórico de Ciudad Juárez, ha permitido ubicar símbolos dotados de significado determinados a través de las configuraciones espacio - temporales acaecidas en la zona centro.

En este sentido, la concepción del espacio como una construcción social, remite a las configuraciones acontecidas en este espacio y su impacto que en las dinámicas sociales que entorno a dichas configuraciones se han desarrollado, lo que también implica un reconocimiento sobre las propias prácticas de la zona y sus modificaciones a partir de esto.

Por ello, existen dinámicas que más allá de caracterizar el centro como lugar de tránsito, de comercio o de esparcimiento, le otorgan valor en conjunto con los elementos físicos considerados como simbólicos, pues estas dinámicas conforman prácticas que se ven relacionadas con el carácter significativo que representa lo denominado centro histórico, en donde la implementación de ciertas acciones que se traducen en creación de espacio público, han generado nuevas percepciones que resultan trascendentes en los actores considerados para referir lo que es el centro.

Es importante señalar que la relación de lo social y el medio construido desde la cual los entrevistados asignan significados a determinados elementos físicos que componen el área, tendría que ver no sólo con la relevancia simbólica de dichos elementos, sino también con las prácticas e interacciones que se generan en relación a ellos, los cuales, determinan esa otra parte intangible en la relación de los social y lo físico en la zona centro, en donde la generación de espacio público finalmente consolida o amplía las prácticas que ahí suceden, promoviendo otras formas de estar en el lugar y por lo tanto de percibirlo.

La producción del imaginario urbano se genera entonces a partir del proceso de asimilación del espacio en relación a las experiencias generadas a partir de las dinámicas de interacción articuladas en relación a los componentes simbólico-significativos ya mencionados y aquí, la posibilidad de los actores en interactuar en y con el propio espacio, se ve ampliada al introducir variantes que eran inexistentes en la zona como la peatonalización de calles o creación de plazas en lugares identificados como riesgosos, que finalmente tienen repercusión directa en las formas de reivindicar el paisaje histórico en el centro.

$\mathrm{Si}$ bien las intervenciones generadas en materia de espacio público dentro de la zona se encuentran perfectamente delimitadas en áreas específicas, las posibilidades que dichas zonas generaron para propiciar nuevas experiencias que finalmente son valoradas acorde a la información proporcionada por los entrevistados y corroborada por la observación en campo, han ampliado las formas mediante los cuales la vida pública en este espacio se ha desarrollado, pues bien, no es entonces la relación que se tiene de los elementos simbólicos como elementos estáticos de contemplación, sino que estos han pasado a ser parte interactiva del espacio público al constituirse como elementos que potencializan los significados dados a la zona, generando la identificación de áreas como simbólicas y significativas por los elementos físicos que las caracterizan y por las prácticas que se generan.

En síntesis, las intervenciones generadas en la zona centro en materia de espacio público, han permito asignar valores positivos que conllevan la parte física y social en el momento en que los usuarios pueden interactuar en dicho espacio bajo nuevas oportunidades de vivir el centro en circunstancias que permiten la interacción con los otros, pero también interactuar con ese referente histórico que finalmente envuelve la zona como parte del legado patrimonial más importante para la ciudad. Aunque ciertamente la zona centro presenta retrasos importantes asociados principalmente a seguridad e imagen, la generación de nuevos espacios públicos supone una oportunidad, pero también un reto para la integración del resto de la ciudad en una zona que a escala urbana, había estado perdiendo importancia de manera gradual. C

\section{REFERENCIAS BIBLIOGRÁFICAS}

Borja, J., \& Muxí, Z. (2000). El espacio público, ciudad y ciudadanía. Barcelona: Electa.

Bourdieu, P. (2000). Poder, derecho y clases sociales. España: Desclée de Brouwer.

Bourdieu, P. (2008). El sentido práctico. Madrid: Editorial Siglo XXI.

Castañeda, A., \& García, J. (2007). Hábitat y espacio público: el caso de los vendedores 
informales en el espacio público físico de Bogotá. Bogotá: Alcaldía Mayor.

Castoriadis, C. (1985). La institución imaginada de la sociedad. Barcelona: Tusquets Editores.

Contreras Delgado, C. (2006). El trabajo doméstico en la construcción del espacio privado (entre las prácticas espaciales y el espacio vivido). En C. Contretas Delgado, \& B. Narváez Tijerina, La experiencia de la ciudad y el trabajo como experiencia de vida (págs. 113-134). Tijuana: $\mathrm{P}$ y $\mathrm{V}$ Editores.

De Certeau, M. (2000). La invención de lo cotidiano I. Artes de hacer. (A. Pescador, Trad.) México, D.F.: Universidad Iberoamericana. Instituto Tecnológico y de Estudios Superiores de Occidente.

Gorelik, A. (2004). Miradas sobre Buenos Aires, historia, cultura y crítica urbana. Buenos Aires: Editorial Siglo XXI.

Güell, P., Frei, R., \& Palestini, E. (2009). El enfoque de las prácticas: un aporte a la teoría del desarrollo. Polis, Revista de la Universidad Bolivariana, 63-94.

Habermas, J. (2006). Entre naturalismo y religión. Barcelona: Paidós.

IMIP. (21 de 05 de 2019). Instituto Municipal de Investigación y Planeación. Obtenido de http://imip.org.mx/Proyectos/Planes

Lalan, J. L. (2011). El paisaje urbano histórico: modas, paradigmas y olvidos . Ciudades, 15-38.

Lindón, A. (2007a). Los imaginarios urbanos y el constructivismo geográfico: los hologramas espaciales. Revista Eure, 37 39.

Louiset, O. (2001). Les villes invisibles, L'informationgéographique. Citado por Lindón, Alicia (2007a)." Los imaginarios urbanos y el constructivismo geográfico: los hologramas espaciales" Revista Eure, 31-46.

Neira, H. (2007). La naturaleza del espacio público. Una visión desde la filosofía. En O. Segovia, Espacios públicos y construcción social (págs. 29-40). Santiago de Chile: Ediciones SUR.

Salazar, S. (2010). Representaciones territoriales. En E. Meza Carpio, Relatos de la memoria. La erosión del Centro Histórico en la ciudad fronteriza. Ciudad Juárez: Universidad Autónoma de Ciudad Juárez.
Sepúlveda, S. (2017). Estado del arte sobre centros históricos en ciudades mexicanas. En A. Pineda, \& M. Velasco, Ciudades y centros históricos: los retos de la vivienda y la habitabilidad. Volumen 1 (pág. 179). 133-167: Universidad Nacional Autónoma de México.

Silva, A. (1992). Imaginarios urbanos. Bogotá y Sao Paulo: cultura y comunicación urbana en América Latina. Bogotá: Tercer mundo editores.

Sorkin, M. (2004). Variaciones sobre un parque temático: la nueva ciudad americana y el fin del espacio público. España: Gustavo Gili.

UNESCO. (2011). Actas de la Conferencia General, 36 reunión. Conferencia General (pág. 218). París: Organización de las Naciones Unidas para la Educación, la Ciencia y la Cultura. 